a inscrição do exercício da Psicanálise na ordem burguesa e na reprodução do modo de produção capitalista. Se antes, como fez na segunda parte do livro, Aricó olhava a Psicanálise de um ângulo exterior, passa agora a olhar esse exterior do ângulo da Psicanálise. Nesse sentido, faz considerações a respeito das características do discurso paranóico e do discurso do ditador. E termina por rever o FreudMarxismo enquanto uma "correspondência linear dos discursos de ambas as correntes" ou enquanto uma "mescla , superposição e reducionismo entre os conceitos mais importantes da Psicanálise e do Materialismo Histórico", sem distinguir a Psicanálise enquanto ciência, ideologia, práti$\mathrm{ca}$ e doutrina. Cita um autor muito conhec do entre nós, Bleger, como um dos que repete este engodo.

Nesse percurso todo, o livro de Aricó tem o efeito de recuperar, de forma intrincada, mas decisiva, o lugar do sujeito na elaboração da ideologta, das teorias, da ciência. Resgata a presença do inconsciente, da lógica da desrazão, do desejo nas práticas de constituição do saber científico. Isto, "sem subordinar a Teoria do Conhecimento à Psicanálise", nas palavras do autor.

Quase sempre os parágrafos sảo densos: há muitas - e preciosas informaçōes escritas de forma a exigir do leitor acentuado exercício de atenção e discriminação. Nem sempre a exposição de suas idéias recebeu destaques formais, ou uma distribuição tal no interior de cada capítulo que facilitasse a compreensão e a leitura.

Este fato, no entanto, não compromete a importância de sua contribuição, especialmente para os psicólogos e os psicanalistas que procuram pensar a Psicanálise para além dos cânones das instituiçōes que reivindicam o monopólio desse saber e desse fazer.
Este fato não compromete, também, sua contribuição para que se distingam as críticas precipitadamente feitas à Psicanálise a partir do marxismo, daquelas que - ainda advindas do marxismo - fazem sentido e podem conduzir à transformação da prática concreta.

Entre afirmações categóricas e dúvidas nem sempre nomeadas, mas certamente estabelecidas no leitor, este livro é um convite à reflexão. Munam-se dos vocabulários de psicanálise, dos operadores para leitura de Lacan, dos dicionários de filosofia e sociologia e, principalmente, das inquietações no exercício cotidiano da profissão, mas não deixem de ler esse livro!

\section{A mulher na Constituinte}

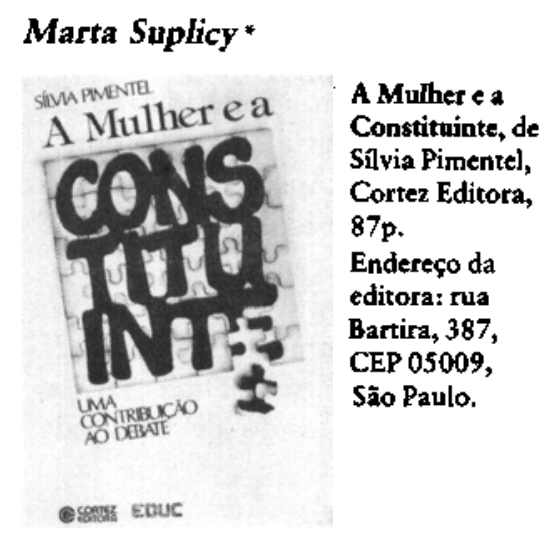

A Mulher e a Constituinte é uma excelente contribuição à compreensão da situação da mulher perante a Lei, no Brasil e internacionalmente.

A autora elogia entusiasticamente as medidas tomadas pelo atual governo (o livro foi escrito antes do pacote

"Aurora dos livros Conversando sobre sexo, Condiça de mulhere De Mariazinha a Maria. do cruzado), tais como o voto do analfabeto, a reforma agrária, a restauração da eleição direta para presidente da República, permissão aos partidos com registros indefinidos para se organizarem na legalidade, anistia aos líderes sindicais etc. Mas não se lembra das reivindicações e críticas que a classe trabalhadora ou os partidos de oposição têm a respeito das limitaçôes da organização sindical, da censura, da precariedade da reforma agrária proposta, da permanência da Lei de Segurança Nacional.

Num tom ufanista, afirma: "O avanço democrático constatado nos permite admitir que este momento pré-Constituinte seja um momento de criação das bases, de um novo ordenamento jurídico-social, que reflita, pela primeira vez no Brasil, a voz de seu povo. (...) A participação dos vários segmentos representativos da sociedade poderá fundar de fato uma Nova República". Lendo frases como estas, fiquei pensando em que país a autora está, pois não existem consideraçōes neste livro sobre o poder econômico, que terá um peso enorme na escolha dos constituinter, t também não se menciona a existência de uma pré-Constituinte formada por 50 "sábios", onde não existe um trabalhador e que, só depois de muita pressão, acolheu uma mulher e um negro.

Ainda na Introdução do livro, Sílvia Pimentel define a Constituição como a "lei máxima da Nação", que "tem por fim estruturar juridicamente o país ao definir sua ordem econômica, política e social, e estabelecer os direitos e as responsabilidades dos indivíduos, dos grupos, do próprio governo, em suas várias instâncias".

A autora aponta as vantagens que, segundo alguns juristas, teria uma Constituição genérica que proporcionaria maior estabilidade e flexibilidade. Mas lembra que a Constituição é 
um documento político para o qual não existem limites de conteúdo, sendo que estes limites devem ser determinados pelos seus participantes. Por isso é ressaltada a importância do momento pré-Constituinte como de aprendizagem política no exercício da democracia.

No primeiro capítulo, faz uma proveitosa revisão com comentários sobre a condição da mulher nas diferen. tes Constituiçōes que o Brasil já teve, em 1824, 1891, 1934, 1937, 1946, 1967 e a emenda constitucional de 1969. Foi somente em 1967 , na Constituiçāo brasileira elaborada após a Declaração Universal dos Direitos do Homem, que tivemos fixado expressamente o preceito que garante a igualdade de todos perante a lei, sem distinção de sexo. No entanto, um exame objetivo da nossa realidade jurídica e social mostra que nem sempre a legislação ordinária e a vida prática têm respeitado o imperativo constitucional. Um exemplo é o tratamento desigual entre o homem e a mulher, dispensado pelos preceitos da lei civil que atribuem somente ao marido, $\mathrm{e}$ não a ambos os cônjuges, a direçāo da sociedade conjugal, o direito de fixar o domicílio da família, o direito de administrar os bens do casal, o direito de decidir em casos de divergência.

Em 1962, foi suprimido do nosso Código Civil o preceito que considerava a mulher casada relativamente incapaz, colocando-a ao lado dos pródigos, silvícolas e menores púberes. Em 84, a Câmara Federal aprovou o projeto de Código Civil que incorporou,praticamente na íntegra, 0 novo Estatuto Civil da Mulher, elaborado por Floriza Verucci e Sílvia Pimentel, o qual elimina a figura do chefe de família e propōe aos cônjuges a direção da sociedade conjugal. O Senado ainda nāo votou essa maté- ria e acredita-se que aguarda a elaboração da futura Constituição.

O segundo capítulo do livro é muito interessante, pois abrange os direitos da mulher em diversos países. $\mathrm{Pa}$ ra mim, o aspecto mais importante foi obvservar a minuciosidade de algumas Constituiçōes e, ao mesmo tempo, entender como cada país coloca especificamente o que acredita ser relevante ou fundamental para seu povo, não querendo correr o risco de vir a ser pouco obedecido ou mal interpretado.

A República Democrática Alemã considera "as famílias numerosas, as mães e os pais solteiros como objeto da ajuda particular do Estado Socialista".

A Constituição cubana, proclamada em 1976, é bastante detalhada no referente aos direitos dos trabalhadores, das mulheres e do matrimônio. "O matrimônio se apóia na igualdade absoluta dos direitos dos cônjuges, os quais devem atentar pela manutenção do lar e pela formação integral dos filhos mediante o esforço comum, de modo que este resulte compatível com o desenvolvimento das atividades sociais de ambos. (...) A mulher goza de direitos iguais aos do homem no campo econômico, político, social e familiar." Para garantir o exercício desses direitos e especialmente a incorporação da mulher ao trabalho social, o Estado cubano está atento para que se proporcionem postos de trabalho compativeis com a sua constituição física; concede-lhe a licença para a maternidade, antes e depois do parto; organiza instituições tais como círculos infantis, semi-internatos e internatos escolares; e se esforça para criar todas as condiçōes que propiciam a socialização do princípio de igualdade.

A China, país onde durante séculos os casamentos foram arranjados entre as famílias, coloca na sua Constituição que "o casamento se baseia totalmente no livre consentimento entre o homem e a mulher". Tendo um enorme problema de excesso de população, acrescenta: "O Estado preconiza e populariza a planificação familiar".

$\mathrm{Na}$ constituição japonesa, em vigor desde 1947, temos no Artigo 24: "O casamento será baseado somente no mútuo consentimento de ambos os sexos e será mantido através da cooperação mútua, tendo como base a igualdade de direitos do marido e da esposa". O Artigo 26 declara: "Todos serāo obrigados a fazer com que todos os meninos e meninas que se achem sob sua proteção recebam edu. cação comum, conforme for estipulado pela lei. Essa educação compulsória será livre".

É interessante notar que a França e os Estados Unidos, que tradicionalmente deram as maiores contribuições à nussa Legislação,são muito va. gos quanto aos direitos da mulher. Ao contrário destes países, muitos dos países do bloco socialista têm a preocupação de garantir direitos econômicos e sociais da população, juntamente com os da mulher.

No terceiro capítulo, Sílvia Pimentel faz consideraçōes sobre a futura Constituição brasileira, enfatizando a importância dos cidadãos terem clara a relação entre a Constituinte e o seu cotidiano. A autora declara que devemos "buscar uma Constituição concisa, portanto sem minúcias e detalhes; a meu ver, a nova Constituição brasileira deverá ser uma Constituição 'situada'. Com isso pretendo dizer que ela será tão mais rica quanto menos abstrata vier a ser. E que, para tal, deverá conter, com razoável explicitação, as principais reivindicaçōes da sociedade brasileira hoje". 